\title{
Shared Modes of Presentation
}

\author{
Simon Prosser \\ University of St Andrews \\ sjp7@st-andrews.ac.uk
}

\begin{abstract}
What is it for two people to think of an object, natural kind or other entity under the same mode of presentation (MOP)? This has seemed a particularly difficult question for advocates of the Mental Files approach, the Language of Thought, or other 'atomistic' theories. In this paper I propose a simple answer. I first argue that, by parallel with the synchronic intrapersonal case, the sharing of a MOP should involve a certain kind of epistemic transparency between the token thoughts of the two thinkers. I then explain how shared words help bring about this transparency. Finally, I show how this account can be extended for thoughts expressed using demonstratives or indexicals.
\end{abstract}

\section{I}

What is it for two people to think of an object, natural kind or other entity under the same mode of presentation (MOP)? Different theories of MOPs (or singular concepts) give different answers. Following Fodor (1998), I shall distinguish two broad kinds of theory. ${ }^{1}$ All versions of inferential role semantics (IRS) hold that a MOP is individuated entirely by its inferential role, which consists of epistemic properties such as inferential relations to specific other concepts, or conditions of warranted application. ${ }^{2}$ All versions of atomism, on the other hand, deny this; they agree with IRS that MOPs are what capture the fine-grained cognitive roles of the thoughts of which MOPs are constituents, but they deny that differences in MOPs are

${ }^{1}$ Fodor 1998 mainly uses the word 'concept', though he does also use 'mode of presentation' in the same way that I am using it here. I take the question of what it is for two individuals to think of an object under the same MOP as equivalent to the question of what it is for two individuals to possess the same singular concept. I shall sometimes use 'concept' in this way.

2 See for example Peacocke 1992. Traditional 'descriptivist' theories of MOPs count as versions of IRS, as do a variety of notions of 'concept' popular among cognitive scientists insofar as concepts, thus construed, are claimed to be the constituents of thoughts. 
to be accounted for in terms of epistemic differences of the kind to which IRS theories appeal. As I shall explain, however, they do take into account certain epistemic relations between tokens in determining which tokens are of the same MOP. ${ }^{3}$ Popular versions of atomism include the Language of Thought (LOT) hypothesis (Fodor 1975, 1998, 2008), all versions of the Mental Files framework (Perry 1980; Recanati 1993, 2012, 2016), and a variety of other theories that individuate MOPs in terms of relations between tokens (for example Kaplan 1990; Schroeter 2012; Schroeter and Schroeter 2014, 2016; Sainsbury and Tye 2012. Richard Heck Jr. (2012) also leans toward a 'no content' view of this general kind, at least with respect to the standard Frege cases.) Some of these theories can also be construed as LOT or mental file theories.

In this paper I shall concentrate on atomistic views, which are generally held to face a greater difficulty than IRS theories in accounting for shared MOPs. I shall put forward a simple view of what it takes for an atomistic MOP to be shared. This will be compatible with at least the spirit of most existing atomistic theories, though there may be some differences concerning details. ${ }^{4}$ In brief, I suggest that sharing a MOP consists in the existence of a transparent epistemic relation between the token thoughts of two speakers, such that communication between them trades on the identity of reference between their token singular terms (or mutatis mutandis for natural kind terms). The broad idea of individuating MOPs in terms of relations of transparency is not entirely new; what I hope to add here is some detail concerning the manner in which this comes about. First, however, I shall very briefly discuss IRS theories in order to put the problem facing atomistic theories in context.

Given a version of IRS it is easy to see what it takes for a MOP to be shared: persons $S_{1}$ and $S_{2}$ think of an object under the same MOP if, and only if, the inferential role of the MOP under which $S_{1}$ thinks of the object

\footnotetext{
${ }^{3}$ The distinction between atomistic and IRS models is similar to the distinction made by Laura Schroeter and François Schroeter (2016) between binding and matching models (respectively); at any rate, the kind of view that I shall discuss counts as both atomistic and binding. Another closely related distinction is between theories that see a difference in MOPs in terms of a difference in content (which is generally true of IRS theories) and those that do not (which is true of atomism). See Heck 2012 for a recent development of a 'no content' approach; though Heck says very little there about interpersonal cases.

${ }^{4}$ Of the existing views, the view developed by Laura Schroeter both individually (e.g. 2012 ) and in joint work with François Schroeter $(2014,2016)$ is the most similar to the view that I shall defend. I discuss some differences below. Some other theories are also similar but say little or nothing about what it is for a MOP to be shared.
} 
is the same as the inferential role of the MOP under which $S_{2}$ thinks of the object. Thus, for example, a descriptivist will say that $S_{1}$ and $S_{2}$ both think of Hesperus under the same MOP if and only if they both think of it as satisfying the same definite description, such as 'the evening star'. A shared MOP is thus seen as a coincidence of individual achievements. Whether a given individual thinks of an object under a given MOP does not in general depend on how anyone else thinks of it.

Given the individualistic nature of IRS-individuated MOPs, it is not surprising that epistemological concerns arise in relation to communication for such theories. It is not typically practical to determine the precise inferential role of another person's thoughts. Consequently, if IRS is correct, then one is rarely in a position to know whether or not one is thinking of an object under the same MOP as someone else. It is not surprising, then, that advocates of such theories have often denied Frege's (1956) view that communication consists in the sharing of thoughts (where 'thoughts' are individuated in a fine-grained manner, by MOPs). Notoriously even Frege is often interpreted as having been willing to loosen the restriction in practice:

In the case of an actual proper name such as 'Aristotle' opinions as to the sense may differ. It might, for instance, be taken to be the following: the pupil of Plato and teacher of Alexander the Great. Anybody who does this will attach another sense to the sentence 'Aristotle was born in Stagira' than will someone who takes as the sense of the name: the teacher of Alexander the Great who was born in Stagira. So long as the Bedeutung remains the same, such variations of sense may be tolerated, although they are to be avoided in the theoretical structure of a demonstrative science and ought not to occur in a perfect language (1892/1966, footnote 2).

Many others have followed Frege, thus interpreted, in thinking that successful communication requires only co-reference. ${ }^{5}$ I think that serious

\footnotetext{
${ }^{5}$ See for example Evans 1982: 399-400 and Dummett 1981: 102-3. There are countless other examples. For dissent from this interpretation of the above passage, however, see May 2006. Richard Heck Jr. $(1995,2002)$ has put forward an in-between view according to which sameness of reference is necessary but not sufficient for communication; communication does not require sameness of MOP but does require that different speakers' MOPs are appropriately related (where the latter condition is taken to be required in order for communication to allow the transmission of knowledge). See Dickie and Rattan 2010 for objections to Heck's positive view. In more recent work Heck (2012) argues strongly against the view that IRS-style MOPs are needed in order to deal with
} 
concerns can be raised about whether this view provides an adequate account of the epistemic relations between two speakers in communication. ${ }^{6}$ My purpose here, however, is not to raise objections to IRS but to discuss the kind of positive view of shared MOPs that can be put forward by the atomist.

Like IRS theories, most atomistic theories have taken as their starting point the synchronic, intrapersonal cases to which Frege drew attention. The standard Fregean criterion of difference for MOPs is well known: for any singular terms ' $a$ ' and ' $b$ ', if a rational subject can assent to ' $a$ is $F$ ' while dissenting or withholding judgment from ' $b$ is $F^{\prime}$, then ' $a$ ' and ' $b$ ' express different MOPs. This is true even if ' $a$ ' and ' $b$ ' share the same reference. Provided we restrict attention to the synchronic intrapersonal case, LOT accounts for the standard Frege cases in terms of the syntax of mental symbols. Syntax is whatever physical property the cognitive system is sensitive to when it sorts symbols by type. Fodor often uses shape as an example, though of course the relevant physical property in actual human beings is likely to be something other than shape. So, according to the LOT hypothesis, if a rational subject assents to ' $a$ is $F^{\prime}$ while dissenting from ' $b$ is $F^{\prime}$, this is because the LOT symbols corresponding to ' $a$ ' and ' $b$ ' differ in syntax. ${ }^{7}$

Frege cases, though he leaves it open whether there might be other reasons to appeal to such MOPs. But he says little about interpersonal (or diachronic) sameness of MOPs; though he argues (correctly, I think) that shared MOPs are not needed in order for there to be psychological laws that generalise across individuals (2012: 164-5). This does not, of course, show that there are no other reasons to appeal to shared atomistic MOPs.

${ }^{6}$ See for example Heck's $(1995,2002)$ argument that the view of communication as requiring only co-reference assumes that communication consists in the transmission of information whereas, Heck argues, communication is also a means for the transmission of knowledge; and this places greater constraints on the relations between different speakers' thoughts. I think Heck is right about this. See also Schroeter 2012 for a further objection with which I have much sympathy, concerning the need to allow that different individuals may think of an object under the same MOP despite substantial differences in their beliefs about the object. I see this as the interpersonal analogue of an argument that says that a subject's opinions about an object may change in almost unlimited ways over time while the subject continues to think of the object under the same MOP.

7 Note, however, that the explanation given above is mechanical rather than psychological; it does not really explain the matter in terms of intentionality, as Fodor (1994: chapter 1) acknowledges (see also Heck 2012: 151-2 for illuminating discussion of this). Below I suggest that, in any case, syntax is not the right way to individuate MOPs, even in the intrapersonal case. 
The mental files framework accounts for such cases in terms of the difference between distinct files of information in the subject's cognitive system. The general idea is that when one thinks of an object (of any kind) one has a mental 'file' of information concerning that object, and the mental file itself constitutes the MOP. One may possess more than one mental file concerning the same individual, and thus more than one MOP of the same individual. The different files normally contain different information, but the information in the file plays no part in the individuation of the MOP. The mere difference in numerical identity between the files themselves constitutes the difference between the MOPs. Thus when someone believes that $\mathrm{a}$ is $\mathrm{F}$, but does not believe that $\mathrm{b}$ is $\mathrm{F}$, it is because the predicate 'is $F^{\prime}$ ' is contained in the ' $a$ ' file but is not contained in the ' $b$ ' file. Even where there is co-reference, predicates are not transferred from one file to another unless the subject explicitly accepts coreference, typically through an identity belief ' $a=b$ '. MOPs thus construed are non-descriptive; they are quite unlike the traditional notion of a MOP.

For atomistic theories, however, the question of what would constitute two subjects sharing the same MOP (that is, thinking of an object under the same MOP) has often been found more problematic than it is for IRS theories. The standard Fregean criterion only tells us when two MOPs are different, and only does that in the synchronic intrapersonal case. Moreover, the notions that atomists have used to explain sameness and difference of MOP in the intrapersonal case often have no obvious application in the interpersonal case. For example, LOT symbols are standardly typed by syntax within an individual. But there is no reason to expect that the physical properties that constitute the syntax of a symbol will ever be duplicated between one individual and another. To keep things simple, let us suppose that there were a LOT, and that in humans the syntax of the LOT symbols were literally just a matter of shape. Suppose that my 'Hesperus' symbols were circular and my 'Phosphorus' symbols were triangular. There does not seem any good reason to suppose that the shapes of your 'Hesperus' and 'Phosphorus' symbols should match up with mine. Perhaps the shapes of your symbols map on to words in different ways to mine, or perhaps your symbols are all different shapes than any of mine. If we were to identify MOPs with syntactic shapes then we should quite likely have to say that MOPs would be shared only very rarely.

MOPs should not be identified with syntactic properties, however. Syntactic properties belong to the wrong descriptive level to be MOPs. 
They help explain the mechanism by which token symbols are treated as belonging to different types within an individual, but they are invisible from the point of view of person-level psychology. It is the latter that MOPs were introduced to explain. This is made vivid when we consider that it seems plausible that there could be a computational system whose symbols gradually changed shape over time, but whose symbol-reading dispositions also changed in a precisely corresponding manner, such that all of the computational properties of the system remained constant. If this happened in a mind the subject need not even be aware of the change, and we should not be inclined to say that the subject's mind contained constantly changing MOPs. This reflects the fact that the LOT notion of a symbol is ultimately a functional, not physical, one.

Much the same applies to the mental files framework, or any other atomistic theory. It is the inferential distinctness of the files - the fact that predicates in one file are kept separate from those in another - that constitutes the difference in MOPs. The details of physical implementation are irrelevant to this. Consequently for both LOT and the mental files framework, and for any other atomistic view, it might appear that there is simply no fact of the matter about whether two subjects think of an object under the same MOP. Fodor has sometimes acknowledged something of this sort:

What, if anything, makes A's thought that Cicero is wet type identical to B's thought that Cicero is wet rather than to B's thought that Tully is wet. (It clearly can't be the spelling, assuming the thoughts are in Mentalese.) [...] It's probably possible to construct cases in which any Direct Reference theorist (not just any Informational Atomist) has to say that there's no question of truth as to which of two necessarily coextensive, syntactically primitive names are translations. (Fodor 2000: 369-70).

Although Frege appears to have made a concession in the footnote quoted above, in some of his other writings he was very clear that communication required sameness of MOP (and thus sameness of thought, given a finegrained individuation of thoughts at the level of MOPs). For example, both Frege's Logic (1997), which is thought to have been written in 1897, and 'The Thought' (1956), which was first published in 1918, contain arguments such as the following (from Logic), in which Frege represents 
disagreement as the interpersonal equivalent of explicit intrapersonal contradiction:

A thought does not belong specially to the person who thinks it, as does an idea to the person who has it: everyone who grasps it encounters it in the same way, as the same thought. Otherwise two people would never attach the same thought to the same sentence, but each would have his own thought; and if, say, one person put $2 \cdot 2=4$ forward as true whilst another denied it, there would be no contradiction, because what was asserted by one would be quite different from what was rejected by the other. It would be quite impossible for the assertions of different people to contradict one another, for a contradiction occurs only when it is the very same thought that one person is asserting to be true and another to be false. So a dispute about something would be futile. There would simply be no common ground to fight on; each thought would be enclosed in its own private world and a contradiction between the thoughts of different people would be like a war between ourselves and the inhabitants of Mars. (1997: 235. $)^{8}$

Frege scholarship is not my chief concern here, and I do not want to suggest that any of the existing atomistic accounts of MOPs are what Frege had in mind. But I do feel that in the above passage Frege hints at an important idea, that a satisfactory account of MOPs should involve a mesh between the metaphysics and epistemology of MOPs such that when two speakers think of an object under the same MOP it follows that there is a kind of direct epistemological engagement between them concerning that object. In what follows I shall offer such an account.

\section{III}

The purpose of individuating MOPs, I assume, is to individuate thoughts (of which MOPs are constituents) in such a way as to correctly describe the cognitive life of a rational thinker. One part of this involves explaining why a rational thinker can fail to know ' $\mathrm{a}=\mathrm{b}$ ' a priori and can simultaneously take differing attitudes to ' $a$ is $F$ ' and ' $b$ is F' even when ' $a$ ' and ' $b$ ' co-refer. The standard criterion of difference for MOPs covers such cases. But this is not the whole story about the individuation of thoughts. There can also

\footnotetext{
8 In interpreting the final sentence of this passage one must of course keep in mind that Frege was writing at a time when space travel seemed almost inconceivable.
} 
be rational connections between a single subject's token thoughts at different times and, I shall suggest, similar rational connections between the token thoughts of different subjects at the same time. These are not covered by the standard criterion. One could stubbornly insist that MOPs were introduced only to deal with Frege cases; but a theory that dealt with Frege cases and also dealt with diachronic intrapersonal and synchronic interpersonal cases would obviously be a better theory.

It has been suggested, I think very plausibly, that an individuation of MOPs should reflect a certain kind of epistemic relation that exists among certain sets of token thoughts. This can be brought out in terms of the inferences that can be made validly by a rational subject. ${ }^{9}$ Consider for example the following two inferences:
Inf1
Inf2
(P1) Hesperus is bright
(P1) Hesperus is bright
(P2) Hesperus is a planet
(P2) Phosphorus is a planet
(C) There is a bright planet
(C) There is a bright planet

Clearly Inf1 is a formally valid inference, and as such it can also be construed as a sequence of thoughts that can occur in the mind of a perfectly rational subject. Inf2, however, is not formally valid, even if Hesperus is Phosphorus. It does not correspond to a rational sequence of thoughts. If, however, we added the premise 'Hesperus is Phosphorus' to Inf2, it would be valid. Assuming that 'Hesperus' and 'Phosphorus' corefer, the difference in validity between Inf1 and Inf2 is constituted by the fact that the two tokens of 'Hesperus' in Inf1 have the same MOP whereas the token of 'Hesperus' in Inf2 has a different MOP from the token of 'Phosphorus'.

I trust that this is all very familiar. Now consider a slight variation on the theme. Consider again someone making an inference like Inf1. Suppose that upon entertaining the second premise a doubt arose in the subject's mind as to whether the first uttered token of 'Hesperus' referred to what the subject would now call 'Hesperus'. No premise equivalent to 'Hesperus is Phosphorus' would be available, because the first token of

\footnotetext{
9 The following argument draws heavily on Campbell 1987, 1994: 73-88. Some hints at a similar kind of argument can be found in Evans 1981: 309. Many others have subsequently taken the same view; see for example Recanati 2012: 47-50.
} 
'Hesperus' occurred at an earlier time and would no longer be available to thought. Instead an interpretive premise would be needed ${ }^{10}$ :

Inf3

(P1) Hesperus is bright

(P2) The token of 'Hesperus' in (P1) stands for Hesperus, therefore:

(P3) Hesperus is bright

(P4) Hesperus is a planet

(C) There is a bright planet

Adding premise P2 would only help if no further questions arose regarding the co-reference of the tokens of 'Hesperus' in P2, P3 and P4. In any case, it is clear that under normal circumstances there is no need for supplementation by interpretive premises such as P2. Instead, to borrow John Campbell's $(1987,1994)$ apt phrase, an inference like Inf1 trades on the identity of reference of the different tokens of 'Hesperus'. According to Campbell, the ability to trade on identity in this way is precisely what we aim to capture by saying that the different tokens of 'Hesperus' in Inf1 share the same MOP. When both tokens share the same MOP there is no epistemic gap between the tokens of the kind that would need bridging by an interpretive premise. Similarly, if Inf3 requires the interpretive premise P2 in order to be valid, the token of 'Hesperus' in P1 does not share the same MOP as the subsequent tokens of 'Hesperus'. The standard Frege cases can be thought of as particular instances of this more general principle. For example, the subject who simultaneously takes differing attitudes to ' $a$ is $F^{\prime}$ ' and ' $b$ is $F^{\prime}$ ' is able to do so without irrationality because of the epistemic gap between the token of ' $a$ ' and the token of ' $b$ '; there is no ability to trade on the co-reference of ' $a$ ' and ' $b$ '. Conversely a subject who cannot rationally take conflicting attitudes to the two thoughts, and who therefore goes directly from believing ' $a$ is $F^{\prime}$ to believing ' $b$ is $F$ ', is in

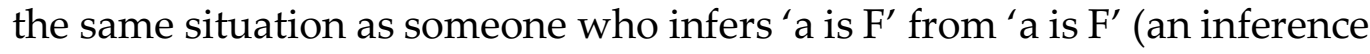
of the form ' $p$ therefore $p$ '). A rational subject cannot reject the inference, and is thus trading on the co-reference of the two tokens, which share the

\footnotetext{
${ }^{10}$ Alternatively one could add a premise to the effect that the tokens of 'Hesperus' in P1 and P2 co-referred. The reason for focusing on the kind of interpretive premise given in the main text will become apparent when we come to the interpersonal case. But the important point is that normally no interpretive premise, of any kind, is needed.
} 
same MOP. I shall therefore take the ability to trade on identity as both necessary and sufficient for sameness of MOP.

I hope that nothing thus far is very controversial; other atomists have made similar claims. We now have another way to think of the distinction between atomist and IRS theories. The atomist holds that, alongside reference, the kinds of inferential relations among tokens just described are fully individuative of MOPs; whereas the IRS theorist, while agreeing that MOP tokens must indeed stand in such relations, holds that MOPs require individuation in terms of further epistemic properties common to all (and only) tokens of the same MOP.

Having got this far, it is not a very big step to understand, at least in very broad terms, what it would be for two people to think of an object under the same atomistic MOP. I shall distinguish two kinds of communication that I call interpretive and transparent communication. Interpretive communication rests on interpretive premises in a way that is analogous to inference Inf3. Like Inf3, interpretive communication does not involve shared MOPs. It is the kind of non-Fregean communication that depends only on co-reference (and an assumption of co-reference by the speakers). Transparent communication, on the other hand, involves trading on identity and requires no interpretive premises. Transparent communication is analogous to Inf1 and involves shared MOPs. I shall now explain these notions in more detail. ${ }^{11}$

\footnotetext{
${ }^{11}$ Dickie and Rattan's (2010) 'Equivalence Class Fregeanism' strikes me as compatible with the broad story thus far - they agree that shared MOPs require a similar kind of epistemic transparency between speakers. They do not give many further details of how the transparency comes about, however, and nothing comparable to what is suggested below. Sainsbury and Tye's (2012) 'originalism' about concepts, however, is not compatible with this kind of story. Although I agree with many elements of their account, including the general claim that concepts are non-eternal abstract continuants, Sainsbury and Tye are committed to the claim that 'necessarily, concept $\mathrm{C} 1=$ concept $\mathrm{C} 2$ iff the originating use of $\mathrm{C} 1$ = the originating use of $C 2$ ' (2012: 44). Since sameness of originating use is neither necessary nor sufficient for a relation of epistemic transparency between tokens (especially if the tokens occur in the minds of different subjects), the originalist account will differ significantly from mine concerning which cases count as shared concepts. It strikes me as a failing of the originalist account that it thus loosens the connection between the individuation of concepts and the epistemic relations between the thoughts of different thinkers.
} 
Suppose Jones and Brown each refer to the same person when they say 'Smith'. Jones says to Brown: 'Smith is tall'. There are two ways in which Brown might understand what Jones is saying. The first way is interpretive. Brown treats Jones's language as an idiolect, distinct from Brown's own language, and therefore relies on an interpretive hypothesis such as the following (in which the subscript 'J' denotes Jones's utterance of 'Smith'):

(1) 'Smith's' stands for Smith

Although we are considering a case in which both speakers can refer to the same individual by saying 'Smith', it would make little difference to their communication if they had different names for that same individual, or spoke entirely different languages. Interpretive hypotheses such as (1) would still facilitate a form of communication in much the same way.

In this way, if Brown believes that whatever Jones says is true, Brown will come to believe that Smith is tall. Note that the grounds for Brown's belief would be undermined if Brown had reason to doubt the interpretive hypothesis (1). In the circumstances envisaged Brown could always coherently wonder whether 'Smith' stands for Smith. If (1) were indeed false, Brown's belief that Smith is tall would be susceptible to a form of error that I shall call error through misinterpretation. ${ }^{12}$ It could turn out that Smith was in fact tall, but if that were the case then Brown's acquisition of a true belief would be just a matter of luck.

Since Brown requires the interpretive hypothesis (1) in order to reach the conclusion that Smith is tall, Brown does not trade on the identity of reference between Jones and Brown's tokens of 'Smith'. The interpretive hypothesis is needed in order to bridge the epistemic gap between the two speakers' thoughts. Consequently, by parity with the intrapersonal case, I suggest that we should regard this as a case in which Jones and Brown think of Smith under different MOPs.

I do not think that all communication is interpretive, however, nor even that this is very commonly the case. Consider a slightly different example, involving a natural kind term. Jones says to Brown:

\footnotetext{
${ }^{12}$ In using this phrase I intend to draw a loose parallel with error through misidentification, and with immunity to error through misidentification (IEM) for the case of transparent communication described below. On the phenomenon of IEM see Shoemaker 1968, and for more recent discussion see the papers collected in Prosser and Recanati 2012.
} 
(2) Beech trees are tall

Suppose further that, like Putnam (1975), Brown cannot distinguish elms from beeches. Jones, however, is an 'expert', someone who can distinguish beeches from other species, and Brown knows this. This is, then, a classic example of linguistic deference. Something very similar can occur with names; I use a natural kind term for the example only because of its familiarity.

In this situation Brown may of course speculate about the reference of 'beech'. If Brown can make an independent identification of some species of tree, $\mathrm{T}$, then Brown can speculate as to whether a beech is a T. But in deferring to Jones concerning the reference of 'beech', Brown does not give an interpretation to Jones's token of 'beech'. Instead, co-reference is automatic; 'beech', as uttered by Brown, refers to whatever it refers to when used by any other member of the linguistic community. ${ }^{13}$ Under those circumstances Brown's belief is immune to error through misinterpretation. Brown cannot coherently wonder whether 'beech' refers to beeches, because Brown has no independent grasp of what a beech is (that is, no independent grasp of what Brown calls a 'beech'). So Brown cannot misinterpret Jones. Instead, Brown trades on the identity of reference between Jones's tokens of 'beech' and Brown's tokens of 'beech'. So when Brown comes to believe that beech trees are tall through accepting Jones's utterance of (2) there is no epistemic gap between the thoughts of the two speakers of the kind that would need to be closed by an interpretive premise. Instead, in such cases, Brown's understanding of Jones is transparent - it involves no interpretive premise. I suggest that in cases of transparent communication, where the speakers trade on identity rather than relying on interpretive premises, the speakers think of the reference under the same MOP. But this claim cannot be made fully clear until a little more has been said about deference and shared words.

\footnotetext{
${ }^{13}$ I am not, however, suggesting that Brown's MOP is characterised by a description such as 'the kind referred to by Jones and others as "beech"'. Brown merely thinks of certain trees as beeches while accepting a kind of implicit commitment to a communal wordusing practice; the reference of 'beech' is then determined by the best interpretation of the set of epistemically connected tokens of 'beech' across the community of users of that word. On this matter I am entirely in agreement with Schroeter and Schroeter 2016.
} 
Deference is often described as an asymmetric relation holding between experts, who can identify the reference, and consumers, who cannot. But this is not the whole story. The standard examples of deference are special cases of a more general phenomenon identified by semantic externalists such as Putnam (1975) and Burge (1979), wherein individuals do not independently determine the references of their words. It is not generally the case that anyone is infallible in the use of a word. Even experts can make mistakes or be forgetful. If a 'pure consumer' is someone who cannot independently rule out any object as a candidate for the reference of a word, then an expert cannot be corrected by a pure consumer. But an expert can potentially be corrected by anyone who is not a pure consumer - other experts, or even those who have only partial knowledge of the reference. For example, there may be a consumer whose only knowledge about beeches is that beeches are deciduous trees. But when a person who would normally be considered an expert, but who is suffering a short-lived confusion, points at an evergreen tree and says 'that is a beech', the consumer, recognising that the demonstrated tree is evergreen, might correct the expert. A rational language user, no matter how expert, should always be open to this kind of correction.

There may be further reasons for complicating the simple distinction between pure experts and pure consumers. For example it is not clear that determinate reference is possible only if there is at least one pure expert, who can identify the reference without help from others. Think of a very complex entity such as a large commercial computer program. Such a program would typically be written by a large team, with each programmer responsible for a different part of the program. We can imagine a scenario in which no complete stored record of the program existed (perhaps the records were all destroyed in an accident). If a question arose as to which computers were running the program in question, there might be no individual capable of giving a definite answer. Yet the group of programmers as a whole might be able to do so by virtue of the expertise distributed among them.

Deference is a manifestation of a deeper phenomenon: the phenomenon of shared languages, containing shared words. Words are public objects, with references that are determined collectively by the speakers of the language. When different speakers utter tokens of the same word then the fact that their tokens co-refer is not the result of a coincidence of individual 
achievements. It is not that each speaker individually determines the reference of their own tokens, while aiming to match their own idiolectic references with the references of the tokens produced by others. I cannot make my tokens of the word 'London' refer to Paris. I can introduce a new word that refers to Paris, and spell it 'London', but in doing so I will not have made a token of the English word 'London' refer to anything other than London (I am assuming, with David Kaplan (1990) and others, that there can be more than one word with the same spelling and pronunciation, due to the different origins of the words). Instead, when a word is shared, and it is correctly recognised, questions about co-reference do not, and cannot, arise. A shared word involves a kind of common commitment that locks together the reference of each token. The fact that different speakers recognise the words of others as tokens of their own words is already sufficient to bring about this locking of reference. (This is not to say that one acquires explicit beliefs about which word is uttered; when Jones says 'beech trees are tall', Brown simply hears (what Brown would express in Brown's own words as) 'beech trees are tall'.) To borrow a phrase commonly used in discussions of co-reference in the intrapersonal case, the co-reference of tokens of shared words is de jure, not merely de facto. This de jure locking of reference comes about precisely because different speakers trade on the identity of reference between tokens produced by different speakers. Deference is a special case of this; the non-expert speaker can lock reference to the tokens produced by the community as a whole, including the experts, just by recognising a shared public word. Maintaining the reference of a shared word is thus a collective enterprise.

There is of course no guarantee that there will never be disagreements among experts. It could turn out that there was no consensus concerning the reference of a word. In that case, however, we should say that the word lacked a determinate reference; we should not say that some experts used the word to refer to one object while others used it to refer to another. It could have been the case that two groups of people used a typographically identical word to refer to different objects, but not while those two groups recognised each other as speakers of the same word.

Suppose Jones and Brown were in conversation, and Jones said 'London is a big city'. Brown might have entertained doubts as to whether Jones was speaking English. But suppose that this was not the case. Brown could not then coherently make the following supposition:

(3) Jones's token of 'London' does not refer to London 
The situation is like that of (2); Brown could only accept (3) by rejecting the assumption that Jones had uttered a token of the English word 'London'. Consequently, as soon as Brown recognised that a token of a specific word in Brown's own vocabulary had been uttered, questions of interpretation could not then arise. Error through misinterpretation would be ruled out. Instead, if Brown accepted what Jones said, Brown would come to share Jones's belief that London is a big city directly, by trading on the identity of reference between Jones's and Brown's tokens of 'London'. Their communication would be transparent, and both would think of London under the same MOP.

I have stressed the preceding points because it is not uncommon for philosophers to assume that to trade on identity is to implicitly presuppose a common reference between tokens, such that this presupposition could turn out to be false. ${ }^{14} \mathrm{I}$ do not think this is quite right. This way of putting things conjures up a picture wherein the references of different tokens are determined independently, and merely presupposed to be the same. I reject this picture, for I do not think that the difference between an explicit assumption of co-reference and an implicit presupposition of co-reference would be enough to account for the sharp epistemological difference between cases of different MOPs and cases of shared MOPs (such as the difference between Inf1 and Inf2), or the difference between de facto and de jure co-reference. It is hard to see why the difference between an assumption occurring explicitly or implicitly would constitute that kind of epistemic difference. So I shall take a strong line here: I hold that trading on identity (and thus sharing MOPs between tokens) does not rest on a fallible presupposition of co-reference between tokens of the same word. The phrase 'rest on' is intended to convey the idea that if co-reference fails, which it might in some cases, it is always because some other presupposition, concerning something other than co-reference, fails. Consequently in such cases it is the latter presupposition that makes the difference; a presupposition of co-

\footnotetext{
${ }^{14}$ I use the word 'presupposition' here in its ordinary sense, meaning an assumption that is made by a subject unconsciously or implicitly, but whose known falsehood would undermine the justification for the subject's belief. Laura Schroeter (2012) uses the word 'presumption' for much the same thing, while Burge (1998) says 'tacit presupposition'. There is a related but more technical use of 'presupposition' in linguistics and philosophy of language, where a presupposition is a property of a linguistic utterance; I do not intend the word in this more technical sense.
} 
reference would, by itself, be idle and could not make any difference regarding the individuation of MOPs.

A number of putative counterexamples may seem pressing. In each case, however, I shall argue that insofar as the epistemic transparency between the tokens rests on a fallible presupposition, it is not a presupposition of co-reference. Only the first of the following cases is interpersonal, but since I have argued that we should treat the interpersonal case as an analogue of the intrapersonal cases, the same principles had better apply in all cases:

Case 1: Jones and Brown refer to different people when they say 'Smith'. Clearly this can happen. But, as stressed above, we should regard these as cases in which Jones and Brown each utter a token of a different name. So there is indeed a presupposition that could in principle fail, even when Jones and Brown share a MOP; but this is a presupposition, implicitly made by Brown, that Jones has uttered a token of the name 'Smith' (i.e. the same name that Brown would utter). It is not a presupposition that Jones and Brown's tokens of the same name 'Smith' share the same reference.

Case 2: Failure to keep track perceptually. I shall discuss demonstratives in more detail below. But I do hold that a subject who keeps track of a visually perceived object, and who first thinks 'that is $F^{\prime}$, then thinks, a short time later, 'that is $G^{\prime}$, where 'is $F^{\prime}$ and 'is $G^{\prime}$ are predicates whose applicability cannot change over time, can then validly infer 'that is both $F$ and $G$ ' by trading on the identity of reference between the tokens of 'that', and thus thinking of the object under the same MOP throughout. Given that the object might be switched for a doppelganger without the subject noticing, however, it might appear that the later tokens would then refer to a different object, thus rendering the inference invalid. I agree with Burge (e.g. 1998) and others, however, that in such cases the different tokens of 'that' may be linked in a quasi-anaphoric manner, such that their references cannot come apart. In a switching case of this kind, the reference of the tokens of 'that' becomes indeterminate, much as would happen if the later tokens of 'that' were replaced by 'it' ('that is $F . .$. and it is also G... etc.'). So the fallible presupposition required for valid inference in such cases is that the object has not switched; it is not a presupposition about the references of the tokens.

Case 3. Burge's (1988) 'slow switching' case. If you learned words like 'water' and 'Smith' on Twin Earth many years ago but were then unknowingly 
transported to Earth several years ago, it is not plausible that the references of your tokens remain indeterminate now. There was a period of indeterminacy when you first changed planet; but by now, your words normally refer to kinds and individuals here on Earth. But what happens when your memories, dating from Twin Earth, interact with your current thoughts? You remember that Smith used to hate swimming in water as a child, but you know that Smith now loves the water. Burge holds that since your first belief about Smith was formed on Twin Earth, your belief that Smith hated the water refers to the Twin Earth version of Smith, and of water (i.e. XYZ). Burge argues that contextual factors determine that within a given train of thought the reference stays constant. When you reason that 'Smith once hated the water, but Smith now loves the water, so Smith has changed' your tokens of 'Smith' and 'water' have their TwinEarthly references throughout; but in other contexts they have their Earthly references.

Laura Schroeter (2007) argues, to my mind convincingly, that Burge cannot be right about this; if a memory of the very same event could shift reference with context in the way that Burge suggests, too many unpalatable consequences would follow. Instead, she argues that words used to state memories derived from Twin Earth would have their Twin Earthly references, which would remain stable; yet the same words, used to state recently-formed beliefs about Smith and water, would have their Earthly references. Consequently when one makes an inference such as the one described above there is a risk of equivocation, and one must presuppose, fallibly, that the tokens of the same words co-refer.

Schroeter's overall view about the individuation of MOPs, which she shares with François Schroeter, is similar to mine in many ways..$^{15}$ But on the issue of whether co-reference has to be presupposed, if I understand Schroeter correctly, then I disagree. The issue is subtle, however; I do agree with Schroeter that the appearance of de jure co-reference does not guarantee co-reference in all cases; but in my view, that's because other presuppositions, not about co-reference, can be false. I do not think that any plausible options of this kind are open to Schroeter, given what she

\footnotetext{
${ }^{15}$ See Schroeter 2012 for a summary of the 'connectedness' model, and also Schroeter and Schroeter 2014, 2016. They give less detail about the interpersonal case than I am giving, but when Laura Schroeter (2012: 182) says 'the default interpretation generated by automatic linguistic parsing is to simply take others' words at face value-as samesaying de jure with your own use of those words' I take it she has in mind something similar to what I am describing as interpersonal trading on identity.
} 
says in response to Burge. ${ }^{16}$

Despite Burge and Schroeter's intuitions to the contrary, I think the natural and intuitive way to treat the slow-switching case is to hold that after a sufficient period on Earth, all of the tokens have their current Earthly references. Right now, in the actual world, let's suppose, I believe that as a child I swam in water (i.e. $\mathrm{H}_{2} \mathrm{O}$ ), that I married Smith (the Earthling), and so on. If I were to discover that in fact I spent the early years of my life on Twin Earth, it would strike me that all of these things that I believe were strictly false. I did not in fact swim in water - I swam in some other stuff (XYZ), and I did not in fact marry Smith - I married someone else, who looks just the same. So what I believed was false. I did, of course, believe many other things that were true: I swam in a clear watery liquid, I married someone with certain characteristics, and so on. Perhaps I have also retained some imagistic content - sights, sounds and so on - that still have their original content. But if such contents are nonconceptual, as many believe, then they need not affect the current references of my concepts. If these intuitions are correct, then Schroeter's argument that co-reference is contingent in such cases doesn't get off the ground.

Note that the cases that Burge and Schroeter discuss concern synchronic relations between tokens; the time differences in such cases concern the sources of the beliefs. But there can also be transparent synchronic relations between tokens; one trades on identity every time one believes ' $a$ if $F^{\prime}$ at time $\mathrm{t}_{1}$ and retains a belief ' $a$ if $F^{\prime}$ at time $\mathrm{t}_{2}$ without the need for an interpretive premise. But these relations do not hold over extended intervals of time without intermediary stages; there are no direct relations of this kind between Twin Earth and much later Earth tokens. Over small enough intervals there is no determinate shift in reference between tokens, given that the intervals can be arbitrarily small.

Case 4. Cross-modal inferences (cf. Campbell 1987). I both see and touch an object, I thereby come to believe 'that is red' and 'that is warm' and I infer 'that is both red and warm'. This can be treated in the same way as case 2: when I trade on identity I lock the references of the tokens together, so there is no fallible presupposition of co-reference. But I do presuppose that

\footnotetext{
${ }_{16}$ Perhaps it could be claimed that the inference rests on a fallible presupposition about not having changed planets between the events described by the different tokens. In any case, if my own view of the case, described below, is correct, then no such presupposition is needed.
} 
the object that I am seeing is the same one that I am touching. If it is not, then the reference of my tokens of 'that' is indeterminate. I could, of course, refer to the seen object and to the felt object independently, such that I could then make sense of the claim 'that (seen) object is not that (felt) object'. But in doing so, I would think of the object under two different MOPs, both of which would be distinct from the MOP under which I think of the object when I trade on identity. A kind of commitment is involved when tokens are locked together in trading on identity, analogous to the case in which one defers, and thus joins a name-using practice, rather than using one's own, newly-created word whose reference one determines independently.

So far we have only considered thoughts expressed using words whose reference does not vary with context. What about context dependent terms such as demonstratives and indexicals? Can the MOPs that they express be shared? If not, this would not in itself undermine what has been said thus far. Perhaps indexical communication is always interpretive, and only communication with context-independent language can involve shared MOPs. I shall argue, however, that MOPs can be shared in all cases. I shall start with 'pure' demonstratives, such as 'that'. Suppose Jones sees an object moving around and says, to Brown:

(4) That is a wasp

Typically Brown will identify some particular object as the best candidate to be the reference of Jones's use of 'that'. But Brown will be open to correction by Jones. There might be several wasps in the vicinity, and Brown may have picked the wrong one. So initially Brown defers to Jones with respect to the reference of 'that'. But as the conversation continues, Jones might temporarily lose track of the wasp and instead defer to Brown, who has kept track of it ('was it that one that we were talking about?'). Hence keeping track of the reference can be a team effort, just as it is with words like 'beech' whose reference is fixed. As with 'beech', the person who first introduces the word starts as an infallible expert, but is open to possible correction thereafter. Given that the references of their tokens of 'that' are locked together, allowing them to trade on identity instead of 
relying on interpretive hypotheses, Jones and Brown think of the object under the same MOP.

There is an obvious complication for demonstratives, however, because the word 'that' may be used to refer to any number of different objects, even within a single sentence ('that is a wasp, but that is a bee'), or to refer to the same object under different MOPs ('that = that' can be informative). This is not only a feature of demonstratives; ambiguous words such as 'bank' are common within a single language, and give rise to similar problems. There are at least two possible ways to deal with such cases. First, along the lines suggested above for ambiguous cases, we could follow Kaplan (1990) in holding that numerically distinct words within a single language can be qualitative duplicates. Thus, instead of one ambiguous word 'bank' there are two different words that have identical pronunciation and spelling, and we use context to determine which word has been uttered. Similarly, one could hold that each new episode of demonstrative reference gives rise to a new word 'that', which continues to exist for the duration of the conversation. On this view the issues concerning deference and shared MOPs are no different for thoughts expressed using 'that' than they are for thoughts expressed using 'beech'. Potential confusion about reference arises only if the audience has failed to correctly recognise which particular 'that' was uttered.

I think we must, however, acknowledge that anyone who correctly understands the word 'that' must understand that it is not a name, but a multi-purpose word that can be used to refer to any number of different things in different contexts. Perhaps a better account would say instead that there are sets of tokens of 'that' which we group together according to contextual factors, and all members of the set are understood to be de jure co-referential. When we converse using 'that', I not only intend my tokens of 'that' to be referentially locked to yours, but I use contextual factors to signal this to you. Provided we recognise each other's tokens of 'that' to belong to this set, the coordinating effects of a shared word are achieved; we can trade on identity of reference between tokens, and think of an object under the same MOP. ${ }^{17}$

\footnotetext{
${ }_{17}$ Strictly speaking one could give a corresponding account for non-demonstrative words such as names; instead of saying that there are two different words 'Smith', we could say that there are two different subsets of the tokens of 'Smith' that are gathered together according to the reference preserving commitments of the speakers. In the case of nondemonstrative words, however, I am not certain that this would amount to anything more than a terminological variant of the account that I have proposed.
} 
There are two prima facie obstacles if we wish to extend the account of shared MOPs to indexicals such as 'here', 'now' and ' $\mathrm{I}$ '. These both relate to the fact that different speakers may stand in different relations to the reference, requiring them to use different indexical terms. For example, if Jones says 'I once saw a reindeer standing here', the nearest equivalent that Brown could say would be 'you once saw a reindeer standing there', assuming that Brown is not standing near to Jones.

The first obstacle is the one to which John Perry (1977) has drawn attention. Different indexicals are associated with systematic differences in behaviour that require explanation in terms of differences in belief states. If I believe that there is danger here, and you believe that there is danger there, we behave differently even if my 'here' and your 'there' tokens refer to the same place. Similar cases are easily constructed with temporal or personal indexicals. We cannot just insist that you and I think of the place under the same MOP and consequently share the same thought, without offering an explanation of the difference in our behaviour. And it is hard to see how this behavioural difference could be explained except through some kind of psychological difference between us.

Perry's solution was to adopt a distinction similar to Kaplan's (1989) distinction between content and character. Content is a function from possible worlds to extensions, whereas character is a function from contexts to contents. Perry and Kaplan both hold that each different indexical term has a different character, and it is character that determines the psychological roles of thoughts and is equated with the MOP. Thus when I believe 'there is danger here' and you believe 'there is danger there', and my 'here' and your 'there' tokens co-refer, we each believe the same content but we do so under different characters, and thus different MOPs. We thus differ in our belief states.

In previous work (Prosser 2005) I have argued that this way of individuating beliefs fails to account for the sense in which a belief can be retained by an individual whose location in space or time changes and who therefore uses different indexical terms at different times. Kaplan (1989: 537-8) himself raised this problem under the heading 'cognitive dynamics'; see also Evans 1981. Suppose that at $t_{1}$ I stand at location L and think 'a reindeer once stood here'. I move away, keeping track of L as I move, and at $t_{2} I$ think 'a reindeer once stood there'. If my belief states at $t_{1}$ and $t_{2}$ are distinct, with no retained singular MOP, as the Kaplan-Perry view suggests, then there is no psychological explanation - no explanation at a 'personal' level - of the occurrence of the belief at $t_{2}$. But this is 
implausible; there seems to be an important sense in which a belief can be retained in such cases. Moreover if we apply the criterion for sameness of MOP in terms of trading on identity then I think of L under the same MOP throughout. For my belief at $t_{2}$ clearly derives from my belief at $t_{1}$, and does so transparently, without relying on an interpretive premise (nor an identity belief 'here = there'. As Evans (1981) observes, no such identity is a possible object of thought, because no person can ever think of $\mathrm{L}$ simultaneously as both 'here' and 'there'.) So there is a strong prima facie case for a retained MOP in such cases; yet this cannot be reconciled with the Kaplan-Perry view, which equates characters with MOPs. In fact this is not surprising, given that the Kaplan-Perry individuation of indexical MOPs is most naturally thought of as a version of IRS, as defined above. ${ }^{18}$

There is, however, a very simple way to explain how there can be a retained singular MOP despite the differences in behaviour in such cases, and the same solution carries over to the synchronic interpersonal case. When one uses an indexical term correctly, one stands in a certain relation to the reference. For example when one refers to a place as 'here' one is at that location; for short, one could say that the place is hereabouts. When one refers to a time as 'now' one, or a temporal stage of oneself, is simultaneous with that time; for short, we say that the time is present. ${ }^{19}$ Similarly, when one refers to a person as ' $\mathrm{I}$ ' one stands in a certain relation to that person. One such relation is identity. But one also stands in other relations to oneself, and the relation that seems relevant here is a certain kind of epistemic-behavioural relation. For example, the person that one refers to as ' $\mathrm{I}$ ' is the person whose bodily states one feels, whose arm one can raise without this being a product of some other action, and so on. But I shall not dwell on the details; my aim here is just to indicate the shape of an account that would allow for shared indexical MOPs. ${ }^{20}$

When one uses 'here' in referring to L one not only stands in the hereabouts relation to $\mathrm{L}$; one also believes this to be the case. That is why one uses the word 'here' rather than 'there'. We can therefore distinguish

\footnotetext{
${ }^{18}$ Note that the kind of character in question would be what Perry (1997) calls a doxastic character, rather than a linguistic character. If these are understood as primitive components of thoughts then the theory is a version of IRS because different doxastic characters will have different inferential roles.

19 Those who accept an A-theory of time may prefer to regard presentness as a primitive property of a time rather than a relation between a person and a time. This is compatible with the general account given above.

${ }^{20}$ For more on these subject-environment relations and their significance for thoughts expressible using indexicals, see Prosser 2015.
} 
two different beliefs associated with an utterance of 'a reindeer once stood here'. First there is the stated belief, which is of the form 'a reindeer once stood at $L^{\prime}$. But there is also a manifested belief: the belief that one manifests by using one indexical term rather than another. So, for example, in using 'here' when referring to $L$ one manifests the fact that one believes ' $L$ is hereabouts'. ${ }^{21}$ When one moves relative to $L$ and one refers to $L$ as 'there', one retains the stated belief ('a reindeer once stood at $L$ '), but there is a change in the manifested belief; one now believes something of the form ' $L$ is thereabouts' (where 'thereabouts' refers to another relation between the subject and L, different from the 'hereabouts' relation). It is the difference in the manifested belief that explains the differences in behaviour associated with the difference between 'here' and 'there'. Nevertheless one can trade on identity through the transition between 'here' and 'there', and thus continue to think of L under the same MOP (and consequently the same fine-grained belief can be retained). The situation is much the same for temporal indexicals where, for example, a use of 'now' manifests the fact that one believes a certain time to be present. There do not appear to be any equivalent dynamic cases for ' $I$ ', but similar principles will apply in the interpersonal case for personal indexicals, as I explain below.

We can extend just the same reasoning to the interpersonal case. When I refer to $L$ as 'here' and you refer to $L$ as 'there', it is because I believe ' $L$ is hereabouts' whereas you believe ' $L$ is thereabouts'. But we both also believe something of the form 'a reindeer once stood at $L$ '. So there is a difference in belief that explains the difference in our behaviour; but, if the conditions for transparent communication are met, we can share the belief that 'a reindeer once stood at $L$ ', with each of us thinking of the place $L$ under the same MOP. Similarly, when I say 'a bear is about to attack me' and you say 'a bear is about to attack you', we may share the belief that 'a bear is about to attack $S$ ' while differing in our relational beliefs about $S$. In most temporal cases both speakers will share the same temporal context; but when temporal contexts do differ between the speakers a precisely analogous account can be given.

The second obstacle to the extension of the account of shared MOPs to the indexical case concerns the fact that speaker and hearer utter different

\footnotetext{
${ }^{21}$ The notion of a belief that is 'manifested' by the use of an indexical is clearly related to certain presuppositions (in the linguist's sense of that word) associated with the utterance of an indexical. I prefer to put things in the way that I do because it is the beliefs, and not any linguistic properties per se, that explain the actions.
} 
words if they are in different contexts. If I say ' $\mathrm{I}$ ' and you say 'you' when both referring to $S$, there is no doubt that we use different words. This obstacle is easier to overcome than the first. The solution appeals to the fact that anyone who properly understands the use of an indexical term must understand the way in which its reference varies with context. Consequently, anyone who understands the word 'here', and encounters a token of it, must understand that the token has the same reference as a token of 'there' in an appropriately related context, and they can rely on this fact in trading on identity. Strictly speaking it is not shared words per se that facilitate interpersonal trading on identity; it is their coordinating role that matters. Provided speaker and audience both understand the way in which a word functions, be it indexical or otherwise, the coordinating role can be achieved. We can imagine a convention according to which if the first speaker says 'Hesperus' then the second speaker says 'Phosphorus' when speaking about the same object. Provided all speakers were aware of this convention it would still be possible to trade on the identity of reference between the different tokens, and MOPs could be shared. If this is not a problem in the Hesperus/Phosphorus case it should not be a problem when different speakers use different indexicals either. Provided the speakers understand how indexical reference depends on context, MOPs can be shared.

\section{VII}

I shall finish by briefly addressing a possible objection. I have been discussing what it is for two people to think of an object under the same MOP. This way of putting things suggests that the MOP under which one speaker thinks of the object stands in the identity relation to the MOP under which the other speaker thinks of the object. However the identity relation is transitive; yet there are cases in which the relation '_ thinks of an object under the same MOP as _' fails to be transitive. Suppose, for example, that persons $\mathrm{A}$ and $\mathrm{B}$ communicate transparently using the word 'beech', as do persons B and C. It does not follow that A and C also communicate transparently using 'beech'. Perhaps A, B and C each pronounce the word slightly differently, such that $A$ and $C$ do not recognise one another's 'beech' tokens as tokens of the same word. A and $C$ therefore communicate only interpretively using 'beech', even though the pairs A-B and B-C communicate transparently. It would seem to follow 
that while $\mathrm{A}$ and $\mathrm{B}$ share a MOP, as do $\mathrm{B}$ and $\mathrm{C}, \mathrm{A}$ and $\mathrm{C}$ do not. This cannot be correct if sharing a MOP literally involves identity of MOPs.

There is much to be said about this. ${ }^{22}$ For now I hope the following observations will suffice. Problems about transitivity already arise in the intrapersonal case for just about any atomistic theory. ${ }^{23}$ A person may have two different mental files for the same object but, upon discovering that there is in fact just one object, the two files may eventually fuse into a single one. Each of the earlier files may be transparently related to the later one, yet not transparently related to one another prior to fusion. The 'same MOP' relation thus fails to be transitive even in the intrapersonal case.

The problem arises ultimately from the fact that atomistic theories do not regard the identity of a MOP as intrinsic to a given token, but instead give only criteria for sameness or difference of MOP between pairs of tokens. Consequently MOPs, as construed by atomists, are continuants; entities for which we can give continuity conditions, but which we cannot individuate merely by their intrinsic natures. There are many other continuants of this kind, including persons and composite physical objects. In all such cases there can be fission or fusion, and the metaphysical problems resulting from this are well known. The problems resulting from fission and fusion for MOPs are very similar to those that arise for psychological continuity theories of personal identity. For every type of solution on offer for personal identity there will be a corresponding type of solution for MOPs. My own view is that the best solution is given by stage theory (Sider 1996, 2001; Hawley 2001). The stage theory view of persons says that strictly speaking a person is an instantaneous temporal stage; a person persists by having many stages that stand in certain relations to one another. On the stage view it can be correct to say, for example, that I was once a child, but this is true if and only if there is a person at an earlier time who is a child and to whom I stand in an intransitive 'I-relation' (which may, for example, be a relation of psychological continuity). Something very similar could be said for MOPs. Strictly speaking the relation that we capture by saying that Brown thinks of $\mathrm{O}$ under the same MOP as Jones is not an identity relation but an intransitive transparency relation. But it is still exactly as true to say that I

22 For the details of my own view, see [Prosser, MS]

${ }^{23}$ Failure of transitivity for mental files in the intrapersonal case is discussed by Pinillos (2011), following a brief indication of a similar problem by Fine (2007: 119). A similar problem was outlined by Taschek (1998). For one way to reply in the intrapersonal case see Recanati 2012: 104-112. 
have retained a belief, or share a belief with someone else, as it is to say that I did various things in the past or will do various things in the future. ${ }^{24}$ As I said, other solutions are possible for MOPs, just as they are for other continuants. I shall leave more detailed discussion of these matters for further work. ${ }^{25,26}$

\section{Bibliography}

Burge, T. 1979. Individualism and the Mental. Midwest Studies in Philosophy, 4: 73-122.

Burge, T. 1988. Individualism and Self-Knowledge. The Journal of Philosophy, 85: 649-663.

Burge, T. 1998. Memory and Self-Knowledge. In P. Ludlow and N. Martin (eds.) Externalism and Self-Knowledge. Stanford, CA: CSLI Publications.

Campbell, J. 1987. Is Sense Transparent? Proceedings of the Aristotelian Society, 88: 273-292.

Campbell, J. 1994. Past, Space and Self. Cambridge, MA: MIT Press.

Dickie, I, and Rattan, G. 2010. Sense, Communication, and Rational Engagement. Dialectica, 64: 131-151.

Dummett, M. A. 1981. Frege: Philosophy of Language. $2^{\text {nd }}$ edition. London: Duckworth.

Evans, G. 1981. Understanding Demonstratives. In H. Parret and J. Bouveresse (eds.) Meaning and Understanding. Berlin/New York: De Gruyter, 280-303. Reprinted in Gareth Evans, Collected Papers. Oxford: Clarendon Press, 1985.

Evans, G. 1982. The Varieties of Reference. Edited by John McDowell. Oxford: Clarendon Press.

Fine, K. 2007. Semantic Relationism. Oxford: Wiley-Blackwell.

Fodor, J. A. 1975. The Language of Thought. Cambridge, MA: Harvard University Press.

\footnotetext{
24 There are obvious similarities between the stage view of MOPs and Fine's (2007) 'semantic relationism'. But by adopting stage theory one need be no more revisionary in one's talk about MOPs than one is in one's talk about persisting persons.

${ }^{25}$ Again, see my [Prosser, MS].

${ }^{26}$ I would like to thank François Recanati, Matheus Valente, Cathal O'Madagain, Sajed Tayebi, Laura Schroeter and audience members in Paris and St Andrews for their helpful comments on talks or written versions of this paper.
} 
Fodor, J. A. 1994. The Elm and the Expert. Cambridge MA/London: MIT Press.

Fodor, J. A. 1998. Concepts: Where Cognitive Science Went Wrong. Oxford: Clarendon Press.

Fodor, J. A. 2000. Replies to Critics. Mind E Language, 15: 350-374.

Fodor, J. A. 2008. LOT 2: The Language of Thought Revisited. Oxford: Clarendon Press.

Frege, G. 1956. The Thought: A Logical Inquiry. Translated by A. M. and Marcelle Quinton. Mind, 65: 289-311.

Frege, G. 1966. On Sense and Reference. In Translations from the Philosophical Writings of Gottlob Frege. Translated by P. Geach and M. Black. $3^{\text {rd }}$ edn. Oxford: Blackwell: 56-78. (Translation of Frege, G. 1892. Über Sinn und Bedeutung. Zeitschrift für Philosophie und Philosophische Kritik, 100: 25-50).

Frege, G. 1997 Logic. In, in Beaney, M. (ed.) The Frege Reader. Oxford: Blackwell: 227-250.

Hawley, K. 2001. How Things Persist. Oxford: Oxford University Press.

Heck, R. 1995. The Sense of Communication. Mind, 104: 79-106.

Heck, R. 2002. Do Demonstratives Have Senses? Philosophers' Imprint, 2: 133.

Heck, R. 2012. Solving Frege's Puzzle. Journal of Philosophy, 109: 132-174.

Kaplan, D. 1989. Demonstratives: An Essay on the Semantics, Logic, Metaphysics, and Epistemology of Demonstratives and other Indexicals. In J. Almog, J. Perry and H. Wettstein (eds.), Themes from Kaplan. Oxford: Oxford University Press.

Kaplan, D. 1990. Words. Aristotelian Society Supplementary Volume, 64: 93119.

May, R. 2006. The Invariance of Sense. The Journal of Philosophy, 103: 111144.

Peacocke, C. 1992. A Study of Concepts. Cambridge MA/London: MIT Press/A Bradford Book.

Perry, J. 1977. Frege on Demonstratives. The Philosophical Review, 86: 474497. Reprinted in J. Perry 1993: The Problem of the Essential Indexical and Other Essays. Oxford: Oxford University Press. Expanded edition 2000: Stanford, CA: CSLI Publications.

Perry, J. 1980. A Problem about Continued Belief. Pacific Philosophical Quarterly, 61: 317-332. 
Perry, J. 1997. Rip van Winkle and Other Characters. In J. Dokic (ed.), European Review of Philosophy, vol. 2: Cognitive Dynamics. Stanford, CA: CSLI Publications: 13-39.

Pinillos, A. 2011. Coreference and Meaning. Philosophical Studies, 154: 301324.

Prosser, S. and Recanati, F. (eds.) 2012. Immunity to Error Through Misidentification: New Essays. Cambridge: Cambridge University Press. Prosser, S. 2005. Cognitive Dynamics and Indexicals. Mind E Language, 20: 369-391.

Prosser, S. 2015. Why are Indexicals Essential? Proceedings of the Aristotelian Society, 115: 211-233.

Prosser, S. [MS]. The Metaphysics of Mental Files.

Putnam, H. 1975. The Meaning of 'Meaning'. Minnesota Studies in the Philosophy of Science, 7: 131-193.

Recanati, F. 1993. Direct Reference: From Language to Thought. Oxford: Blackwell.

Recanati, F. 2012. Mental Files. Oxford: Oxford University Press.

Recanati, F. 2016. Mental Files in Flux. Oxford: Oxford University Press.

Sainsbury, R. M, and Tye, M. 2012. Seven Puzzles of Thought. Oxford: Oxford University Press.

Schroeter, L. 2007. The Illusion of Transparency. Australasian Journal of Philosophy, 85: 597-618.

Schroeter, L, 2012. Bootstrapping Our Way to Samesaying. Synthese, 189: 177-197.

Schroeter, L, and Schroeter, F. 2014. Normative Concepts: A Connectedness Model. Philosophers' Imprint, 14: 1-26.

Schroeter, L, and Schroeter, F. 2016. Semantic Deference Versus Semantic Coordination. American Philosophical Quarterly, 53: 193-210.

Sider, T. 1996. All the World's a Stage. Australasian Journal of Philosophy, 74: 433-453.

Sider, T. 2001. Four Dimensionalism. Oxford: Oxford University Press.

Shoemaker, S. 1968. Self-Reference and Self-Awareness. The Journal of Philosophy, 65: 555-567.

Taschek, W. W. 1998. On Ascribing Beliefs: Content in Context. The Journal of Philosophy, 95: 323-353. 